\title{
Analysing post-earthquake landslide activity using multi-temporal landslide inventories near the epicentral area of the 2008 Wenchuan earthquake
}

\author{
Chenxiao Tang, Cees J. Van Westen, Hakan Tanyas, and Victor G. Jetten \\ Faculty of Geo-Information Sciences and Earth Observation (ITC), University of Twente, Twente, the Netherlands \\ Correspondence to: Chenxiao Tang (c.tang@utwente.nl)
}

Received: 29 May 2016 - Published in Nat. Hazards Earth Syst. Sci. Discuss.: 3 June 2016

Revised: 21 October 2016 - Accepted: 9 November 2016 - Published: 12 December 2016

\begin{abstract}
Large earthquakes in mountainous regions may trigger thousands of landslides, some active for years. We analysed the changes in landslide activity near the epicentre of the 2008 Wenchuan earthquake by generating five landslide inventories for different years through stereoscopic digital visual image interpretation. From May 2008 to April 2015, 660 new landslides occurred outside the coseismic landslide areas. In April 2015, the number of active landslides had gone down to 66 , less than $1 \%$ of the co-seismic landslides, but still much higher than the preearthquake levels. We expect that the landslide activity will continue to decay, but may be halted if extreme rainfall events occur.
\end{abstract}

\section{Introduction}

Large earthquakes can cause huge losses to human society due to shaking ground, fault rupture, liquefaction, tsunamis, and also due to co-seismic landslides that can be triggered in mountainous areas. Some examples of earthquaketriggered landslide events are the 1976 Guatemala earthquake $\left(M_{\mathrm{w}}=7.5\right)$, with 50000 landslides (Cruden and Varnes, 1996), the 1994 Northridge earthquake $\left(M_{\mathrm{w}}=6.7\right)$ in California with more than 11000 landslides (Soeters and van Westen, 1996), the 1999 Chi-Chi earthquake $\left(M_{\mathrm{w}}=7.6\right)$ in Taiwan with 26000 co-seismic landslides (Cheng et al., $2005)$, and the 2008 Wenchuan earthquake $\left(M_{\mathrm{w}}=7.9\right)$ in China with more than 56000 landslides (Dai et al., 2011). In areas that have been affected by such large earthquakes, the threat of landslides persists in the years following the earthquake because huge amounts of deposits loosened by the earthquake on hillslopes provide sufficient source material for landslide reactivation and debris flow occurrence during heavy rainstorms. For example, after the 1999 ChiChi earthquake $\left(M_{\mathrm{w}}=7.6\right)$, a number of extreme precipitation events reactivated the co-seismic landslides and triggered several catastrophic mass movements, such as the debris flow that destroyed Daxing village on 30 July 2001 and the landslide that buried Hsiaolin village forming a barrier lake in 2009 (Dong et al., 2011). Many studies about post-earthquake landslides were carried out after the Chi-Chi earthquake, including Fan et al. (2003), Chang et al. (2006), and Lin et al. (2006).

The devastating Wenchuan earthquake occurred in the western part of Sichuan province in China on 12 May 2008. In the years following the earthquake, several catastrophic debris flows occurred, demonstrating many of the postseismic landslide problems. Some significant examples are the debris flows that destroyed part of the town of Beichuan on 24 September 2008, the debris flow that dammed the Min River on 13 August 2010, and the debris flow that damaged the village of Qipangou on 10 July 2013 (Tang et al., 2009; $\mathrm{Xu}$ et al., 2012). These post-earthquake mass movements highlighted the need for more research to provide critical information for assessing post-earthquake landslide hazards as a basis for reconstruction planning in earthquake-affected mountainous areas.

The majority of the research in the Wenchuan area thus far has focused on the analysis of case studies (e.g. Xu et al., 2012; Ni et al., 2011; Tang and Liang, 2008), coseismic landslides (e.g. Dai et al., 2011; Fan et al., 2012; Gorum et al., 2011), and post-seismic landslide mechanisms (e.g. Zhuang et al., 2012; Zhang et al., 2013; You et al., 
2011). Some also studied vegetation recovery (e.g. Liu et al., 2010; Lu et al., 2012; Wang et al., 2014). Limited research has concentrated on the long-term evolution of landslide activities and the changes in the geographic environment after earthquakes. Hovius et al. (2011) analysed the long-term erosion and mass balance effects of the Chi-Chi earthquake. They concluded that the enhanced mass wasting and sediment removal after the earthquake was more than 5 times the pre-earthquake rate, and it required about 6 years to return to pre-earthquake levels. For the Chi-Chi earthquake this was reported by several authors (Lin et al., 2008; Shieh et al., 2009; Shou et al., 2011a, b). For the Wenchuan earthquake area, some researchers have studied the short-term (within 3 years) changes in landslide reactivation after storms (Tang et al., 2011; Wang et al., 2014). Huang and Fan (2013) made a prediction that it will take about 20 years before the landslide activity will return to pre-earthquake levels; however, this was not based on long-term studies.

The objective of this research is to analyse the changes in landslide activity after the Wenchuan earthquake based on detailed landslide inventory maps generated from seven highresolution images from 2005 to 2015 in order to contribute to the long-term monitoring of post-earthquake landslide activity.

\section{Study area}

The study area (Fig. 1) is located near the epicentre of the Wenchuan earthquake, around Yingxiu and Longchi, in Sichuan province, China. The study area covers approximately $179 \mathrm{~km}^{2}$. The elevation of this area varies from 767 to $3950 \mathrm{~m}$, with an average of $1736 \mathrm{~m}$. The Yingxiu area, in the western part of the study area, is steeper than the Longchi area in the eastern part. Areas with slopes steeper than $45^{\circ}$ cover $21 \%$ of Yingxiu and only $2 \%$ of the Longchi area. The major fault rupture of the Wenchuan earthquake (YingxiuBeichuan fracture) passes through the area. The predominant lithologies are granite (59\% of the area), diorite ( $22 \%$ of the area) in the western part, and some sedimentary rocks in the south-eastern part, which are bounded by faults. The climate is humid subtropical with an annual average temperature of $13^{\circ} \mathrm{C}$. The area was densely covered by shrubs and broadleaf forest, with sparse patches of coniferous forest before the earthquake. Buildings and agricultural lands are mostly distributed along the rivers (Fig. 2a). As a result of the earthquake, large, bare areas caused by landslides covered the slopes and their foot zones (Fig. 2b). Years after, most slopes affected by landslides are covered by shrubs and grass. The average yearly precipitation in the area is $1134 \mathrm{~mm}$, and $70 \%$ of the precipitation occurs from June to September. The highest precipitation is in August, with an average monthly rainfall of $289.9 \mathrm{~mm}$. The recorded maximum monthly, daily, and hourly precipitation amounts are 593, 234, and $84 \mathrm{~mm}$ respectively (Liu et al., 2010).

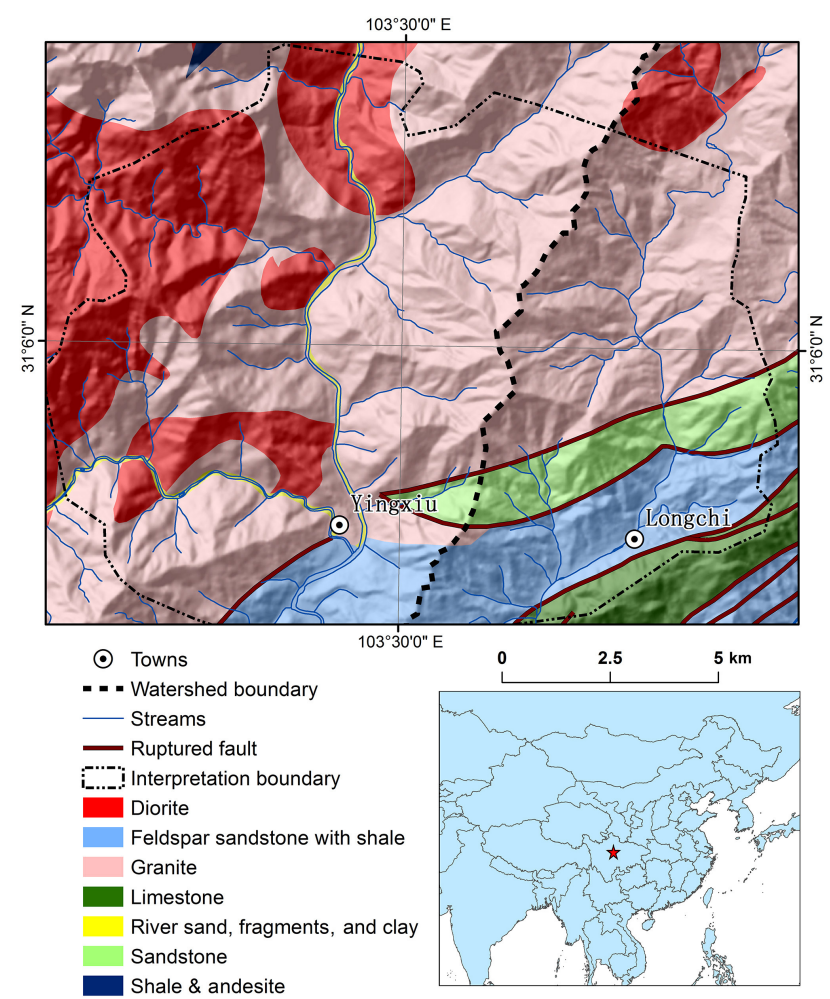

Figure 1. Map of the study area. The western part of the thick dotted line is the Yingxiu area and the eastern part is the Longchi area. The area for which the landslide interpretation was carried out is shown as a polygon with a thin dotted border.

\section{Data and methods}

\subsection{Remote sensing data and pre-processing}

We have acquired multiple remote sensing images from various sources for generating the multi-temporal landslide inventories. Based on the resolution, cloud coverage, and shadows, a total of six images taken in 2008, 2009, 2011, 2013, and 2015 were selected to monitor the landslide activities after the earthquake and one image was selected from 2005 , representing the pre-earthquake situation (Table 1). To assist landslide digitizing with stereo visualization and to analyse controlling factors of post-seismic landslide activities, a digital elevation model (DEM) derived from $20 \mathrm{~m}$ interval contour lines was collected from the State Key Laboratory of Geo-hazard Prevention and Geo-environment Protection (SKLGP) in Chengdu, Sichuan province.

Erdas and ArcMap were used for producing the image dataset. The Pleiades and the Worldview 2 images have very high resolution and are geometrically consistent with the dataset provided by SKLGP. Thus, they were used as the reference images for geometric calibration. The other satellite images were orthorectified with the DEM in Erdas. Dozens of GCPs and hundreds of auto tie points were used to cali- 
Table 1. Data used in this research. The two images taken in 2008 have $7 \%$ of the study area covered by clouds on both images. The other images are cloud free. Information area $(\%)$ represents the percentage of the area not covered by clouds and the inside of the image boundaries.

\begin{tabular}{|c|c|c|c|c|c|c|}
\hline Type & Source & $\begin{array}{l}\text { Acquisition } \\
\text { date }\end{array}$ & $\begin{array}{r}\text { Resolution } \\
(\mathrm{m})\end{array}$ & $\begin{array}{r}\text { Information } \\
\text { area }(\%)\end{array}$ & Band & Usage \\
\hline \multirow{7}{*}{$\begin{array}{l}\text { Images } \\
\text { Generating } \\
\text { landslide } \\
\text { inventories }\end{array}$} & Spot 5 & Jul 2005 & 2.5 & 95 & Multispectral & \\
\hline & Aerial photographs & May 2008 & 1 & 69 & RGB & \\
\hline & \multirow{2}{*}{ Spot 5} & Jul 2008 & 2.5 & 74 & Panchromatic & \\
\hline & & Feb 2009 & 2.5 & 100 & Pancharomatic + multispectral & \\
\hline & Worldview 2 & Apr 2011 & 1 & 100 & Pansharpened & \\
\hline & Pleiades & Apr 2013 & 0.5 & 69 & Panchromatic + multispectral & \\
\hline & Spot 6 & Apr 2015 & 1.5 & 97 & Pansharpened & \\
\hline DEM & $\begin{array}{l}\text { Government, } \\
\text { academic institute }\end{array}$ & $\begin{array}{l}\text { Pre- } \\
\text { earthquake }\end{array}$ & 25 & - & - & $\begin{array}{l}\text { Digitizing } \\
\text { landslides, factor } \\
\text { analysis }\end{array}$ \\
\hline Lithology & $\begin{array}{l}\text { Official geology } \\
\text { map, geological } \\
\text { survey }\end{array}$ & - & - & & & Factor analysis \\
\hline \multirow{4}{*}{$\begin{array}{l}\text { Peak rainfall } \\
\text { intensity and } \\
\text { cumulative } \\
\text { precipitation }\end{array}$} & Tang and Liang (2008) & 2008 & & & & \multirow{4}{*}{$\begin{array}{l}\text { Analysing post- } \\
\text { seismic } \\
\text { landslide } \\
\text { activities }\end{array}$} \\
\hline & Liu et al. (2010) & 2009 & & & & \\
\hline & Ma et al. (2011) & 2010 & & & & \\
\hline & $\begin{array}{l}\text { Rain gauges } \\
\text { installed by } \\
\text { SKLGP }\end{array}$ & 2011-2015 & & & & \\
\hline
\end{tabular}

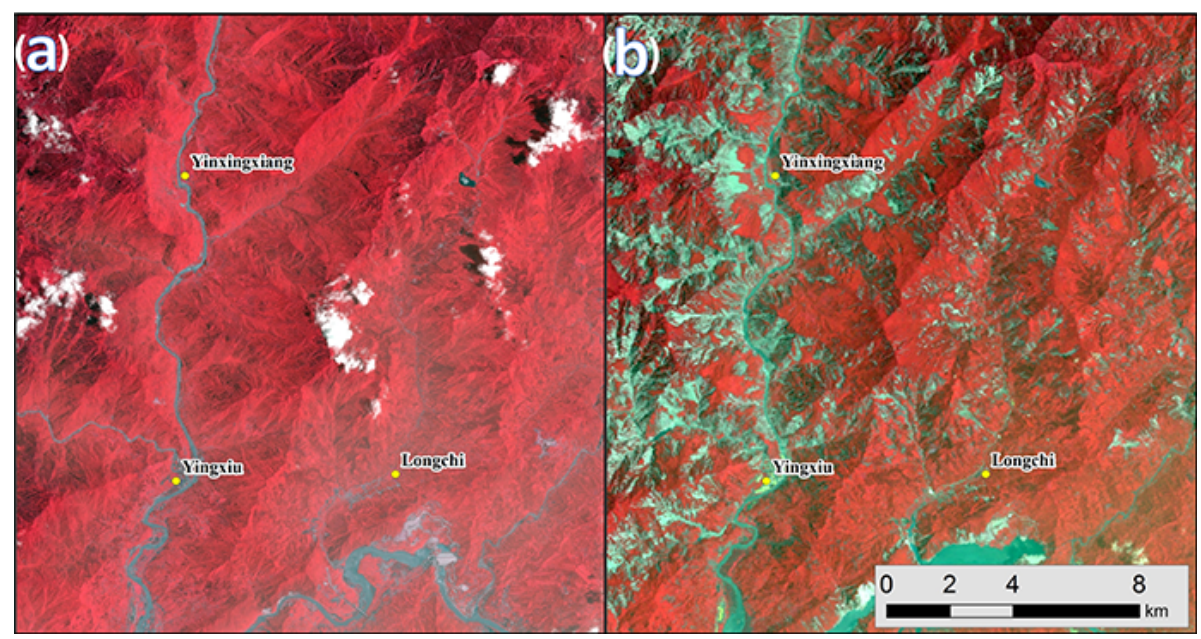

Figure 2. False colour satellite images before (a) and after (b) the earthquake, showing the large extent of forested areas before the earthquake and the numerous slopes lacking vegetation due to landslides in the post-earthquake image.

brate the images in Erdas IMAGINE Autosync Workstation. One of the problematic images was the 2009 Spot 5 image, which showed geometric errors in the steep mountain peak areas. About 180 co-seismic landslides were located in these problematic areas. The mass movement traces with bright tones and loss of vegetation could still be seen except for the pre-existing small landslides. A simplification was applied for the inventory of 2009: all of the unenlarged preexisting small landslides were considered dormant. By digi- tizing post-seismic landslides based on the co-seismic landslide inventory, the landslide boundaries were kept consistent, minimizing the errors caused by image quality.

\subsection{Multi-temporal landslide inventories}

Digital stereoscopic image interpretation was used for mapping the landslide inventories. The images were combined with the DEM, and a series of artificial stereo images 

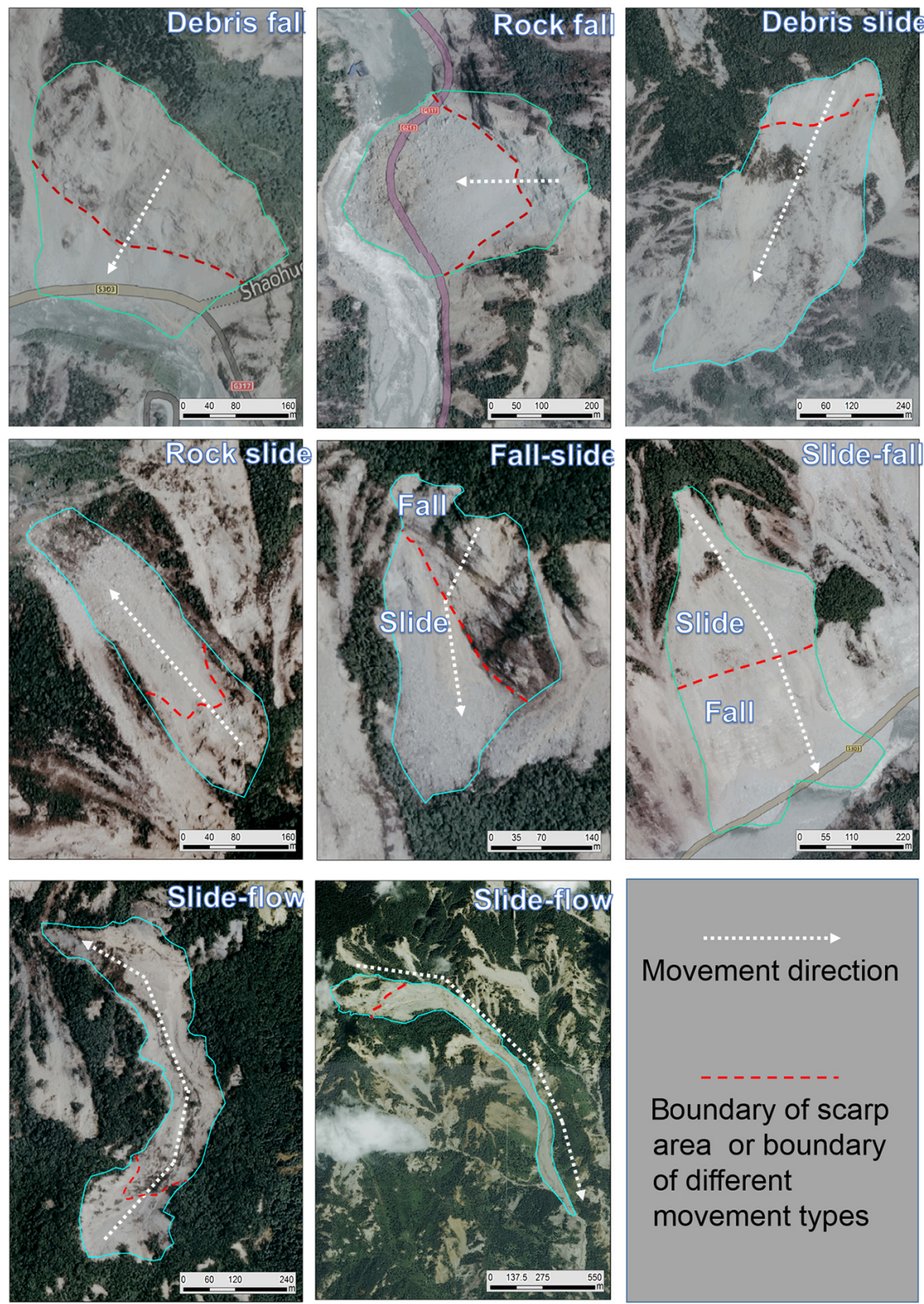

Figure 3. Examples of landslide classifications used. The background is the aerial photo taken in 2008.

were generated using ArcScene. Co-seismic landslides were digitized first. We carefully compared the pre- and postearthquake images to determine which of the landslides were co-seismic and which ones pre-existed the earthquake. Existing landslide inventories, generated by Gorum et al. (2011), Dai et al. (2011), Xu et al. (2014), and Li et al. (2014) were evaluated. These inventories did not match very well with each other, and they also did not match with the georectified remote sensing images used in this study. Therefore, new co-seismic landslide inventory mapping was also carried out for the study area. The mapping accuracy was kept at a high level by comparing the landslides on different images and by checking the landslides in the field. All the landslides were categorized based on the system proposed by British Geological Survey (BGS), which follows the scheme based on Liu et al. (2010) and Fan et al. (2012). The landslides were classified by their material component and mass movement types (Fig. 3). Two types of material were differentiated: debris and rock. Debris, a mixture of soil and rock fragments, was interpreted from images when a fine material texture covered most of the deposition area. The parent material was interpreted as rock when rock fragments or blocks or textures of 
Table 2. Attributes collected for the landslide inventories.

\begin{tabular}{ll}
\hline Attributes & Description \\
\hline ID & Landslide identifier \\
Material & The material component of the landslide (rock or debris) \\
Mass movement type & The mass movement type (fall, slide, flow, fall-slide or slide-flow) \\
No information & The landslide is covered by clouds or located outside of the image boundary \\
Landslide activity level & The landslide activity class $(0:$ dormant; $1:<$ one-third active, $2:$ one-third to two-thirds active; $3:>$ two-thirds active). \\
Vegetation cover level & The vegetation cover class $(0:$ vegetated; $1:>$ two-thirds vegetated, $2:$ one-third to two-thirds vegetated; $3:<$ one-third vegetated). \\
New landslide & Landslide that does not occur on pre-existing landslide. The year in which it is first seen is indicated \\
Area & The area of the landslide in $\mathrm{m}^{2}$ \\
Lithology & The major lithology within the scarp area of a landslide polygon \\
Aspect & The orientation of slopes in the scarp area \\
Max slope angle & The highest slope angle that is calculated from the DEM in a landslide polygon \\
\hline
\end{tabular}

rock deposits could be clearly seen on the images. Comparing images of different years also helped to distinguish debris and rock since landslides with rock blocks are re-vegetated much more slowly than debris-related mass movements, even when there is no further landslide activity observed.

We differentiated the following mass movement types: fall, slide, and flow. In the case of fall, materials fall from steep cliffs with little additional displacement. Bedrock can be seen very clearly in the scarp area and the accumulation area often tends to be cone shaped. Slide-type movements are characterized by clear back scarps, and the identification of a sliding mass, either translational or rotational in form. Flowtype movements are mostly confined to channels and occur mostly as debris flows.

Combinations of movement types were also observed. The most frequent combinations were slide and flow, and slide and fall types. Fall-slide, a combination of falling and sliding, can be observed when a fall-type movement occurs on a steep slope and the deposits slide down further during or after deposition. Slide-fall movements initiate when a slide on top of a steep cliff, and the materials that subsequently slid, fall over a cliff. A very common combination of landslide types is slide-flow, where the source areas of a debris flow are formed by one or more slide-type movements. This is more difficult to identify in post-seismic landslides since they are often caused by a combination of initiation features, such as accelerated erosion, bank failure, and shallow landslides in the sediment source areas. For post-earthquake landslide inventories we only use fall, slide, and flow to represent their movement types since the combined types are difficult to identify for reactivation of co-seismic landslides, and the predominance of debris flows caused by different processes made it problematic to differentiate.

The earthquake-induced landslides were interpreted using an orthorectified mosaic of very-high-resolution colour aerial photographs taken shortly after the earthquake and two Spot 5 images: one from 2005 and one taken shortly after the earthquake. The satellite image from 2005 revealed almost no landslide activity prior to the earthquake. Landslides were identified based on image characteristics such as tone, texture, shape, and pattern, and by using topographic, vegeta- tion, and drainage indicators identified through stereoscopic image interpretation (Soeters and van Westen, 1996). Individual landslides were identified based on their unique scarp areas, even though the accumulation areas were often merged downslope. Each landslide polygon was assigned a unique identifier. Areas covered by clouds were digitized and were not considered for the 2008-2009 change analysis.

The interpretation of post-earthquake landslides was carried out by comparing remote sensing images of different years, starting from the earliest post-earthquake image in 2009. The co-seismic landslide inventory was used as the basis for the inventory of the post-earthquake landslides of the following year. Then this inventory was used as the basis for the next, and so on. All landslide polygons from the co-seismic landslide inventory were classified for each period with a landslide activity level and a vegetation cover level. Changes caused by the enlargement of existing landslides and newly triggered landslides were included in the digital inventories, and changes in landslide classifications were also marked in the associated attribute tables. If in a later year landslide activity was confined within the polygon of a pre-existing landslide, no digitization was done and the polygon of the pre-existing landslide was assigned with a landslide activity class value based on the level of the activity. This was done for all the consecutive years. If there is no activity in a pre-existing landslide polygon, the landslide is considered a dormant landslide. Several tools in ArcMap were used to calculate attributes for the landslide polygons related to area, slope, aspect, and major lithology in the landslide polygons. The attribute table of the landslide inventories is shown in Table 2.

The landslide activity levels were defined based on the changes in the diagnostic features between remote sensing images taken in different periods. The vegetation cover alone does not determine whether a landslide is active or not. A landslide can be bare and dormant or partly covered by vegetation and active. The following landslide activity classes were used: level 0 , no landslide activity and the landslide is dormant; level 1, less than one-third of the area of a landslide is active; level 2 about one-third to two-thirds of the area of 
Table 3. The relation between lithology and co-seismic landslides.

\begin{tabular}{lrcrr}
\hline Lithology type & $\begin{array}{r}\text { Number of } \\
\text { landslides }\end{array}$ & $\begin{array}{c}\text { Number } \\
\text { density } \\
\left(\begin{array}{l}\text { landslides/ } \\
\left.\mathrm{km}^{2}\right)\end{array}\right.\end{array}$ & $\begin{array}{r}\text { Area of } \\
\text { landslides } \\
\left(\mathrm{km}^{2}\right)\end{array}$ & $\begin{array}{r}\text { Area } \\
\text { density } \\
(\%)\end{array}$ \\
\hline Diorite & 1208 & 34.2 & 16.4 & 46 \\
Granite & 4713 & 46.4 & 34.1 & 34 \\
Sandstone & 522 & 48.3 & 2.5 & 23 \\
$\begin{array}{l}\text { Feldspar sandstone } \\
\text { with shale }\end{array}$ & 284 & 12.3 & 1.6 & 7 \\
\hline
\end{tabular}

a landslide is active; level 3, more than two-thirds of a landslide is active or the landslide is newly formed.

The vegetation cover level was judged by the area of vegetation cover on landslides and was classified into four classes: level 0 , most area of the landslide is covered by vegetation; level 1 , more than two-thirds of the landslide is covered by vegetation; level 2, one-third to two-thirds of the landslide is covered by vegetation; level 3 , less than one-third of the area of a landslide is covered by vegetation.

\section{Results}

\subsection{Co-seismic landslides}

The co-seismic landslide inventory map for the study area is shown in Fig. 4. The co-seismic landslide inventory contains 6727 landslides with a total area of $54.6 \mathrm{~km}^{2}$, covering about $29.4 \%$ of the $179 \mathrm{~km}^{2}$ interpretation area. The average and median area of the co-seismic landslides are 8122 and $2141 \mathrm{~m}^{2}$ respectively. About $25 \%$ of all the landslides have an area of $100-800 \mathrm{~m}^{2}$. When we apply the empirical area-volume relationships presented by Guzzetti et al. (2009), the total volume of the interpreted co-seismic landslides is $0.48 \mathrm{~km}^{3}$. Obviously the size of the individually mapped landslides has a large influence on the volume estimation, and the degree of generalization of a landslide inventory is therefore of importance. When we use the same relation using the inventory of Dai et al. (2011), which has large landslide polygons merging multiple individual landslides, the result is $0.63 \mathrm{~km}^{3}$. Most of the large earthquaketriggered landslides are in the western part of the study area, which has a steeper terrain and is closer to the epicentre. The mean size of the landslides in the western part is about $10000 \mathrm{~m}^{2}$. Most of the co-seismic landslides in the eastern part of the study area are small and medium-sized with an average area of $3782 \mathrm{~m}^{2}$. Table 3 shows the relation between lithology and landslides, which shows that most landslides occurred in granite and diorite.

Table 4 gives a summary of the co-seismic landslide inventory generated in this study. The most common landslide type was debris slides (5604 out of a total of 6727), due to the strong topographic amplification that led to the
Table 4. Co-seismic landslide types.

\begin{tabular}{lrrrrr}
\hline & Slide & Fall & Fall-slide & Slide-flow & Sum \\
\hline Debris & 5604 & 272 & 124 & 171 & 6171 \\
Rock & 262 & 241 & 53 & 0 & 556 \\
Sum & 5866 & 513 & 177 & 171 & 6727 \\
\hline
\end{tabular}

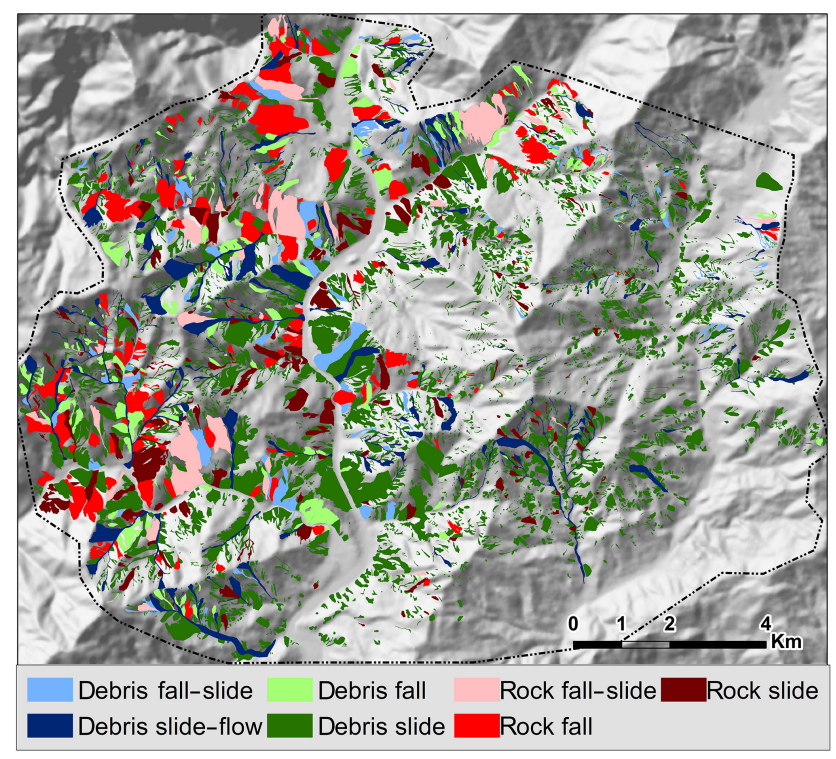

Figure 4. Co-seismic landslide inventory.

failure of the weathering soil mantle. In specific locations, where the structural geology was favourable, rock slides took place along discontinuities (262 events). In a number of cases the presence of steep cliffs resulted in fall-type movements (513 events) or a combination of fall and slide types (177). It is remarkable that the number of flow-related co-seismic mass movements was relatively limited (171 cases), which is also due to the fact that the earthquake occurred during the dry season.

Both the number of landslides in our inventory and the area affected are much higher than the values reported by Dai et al. (2011). They mapped only 661 landslides as polygons with a total area of $33.8 \mathrm{~km}^{2}$ within the Yingxiu part of the study area. Due to clouds in their available image they did not map the landslides in the Longchi area. In our inventory, we distinguished 4175 landslides with an area of $45.9 \mathrm{~km}^{2}$ in the Yingxiu area. Gorum et al. (2011) mapped 1141 landslide initiation points in our interpretation area. Our inventory contained approximately 6 times more landslides than the inventory mapped by Dai et al. (2011) and 3.5 times more than the inventory mapped by Gorum et al. (2011). This difference is partly caused by the different aims of the studies, as the previous studies mapped landslides in the entire area affected by the Wenchuan earthquake. Additionally, the availability of very-high-resolution aerial photographs taken shortly af- 
Table 5. Summary information for the co-seismic landslide inventories collected for the study area. $B$ is the power-law exponent of the frequency-area distribution (FAD).

\begin{tabular}{lrrrrrrr}
\hline Inventory & $\begin{array}{r}\text { Total } \\
\text { number of } \\
\text { landslides }\end{array}$ & $\begin{array}{c}\text { Total } \\
\text { landslide } \\
\text { area } \\
\left(\mathrm{km}^{2}\right)\end{array}$ & $\begin{array}{r}\text { Minimum } \\
\text { landslide } \\
\text { area }\left(\mathrm{m}^{2}\right)\end{array}$ & $\begin{array}{r}\text { Maximum } \\
\text { landslide } \\
\text { area }\left(\mathrm{m}^{2}\right)\end{array}$ & $\begin{array}{r}\text { Average } \\
\text { landslide } \\
\text { area }\left(\mathrm{m}^{2}\right)\end{array}$ & $\beta$ & $\begin{array}{r}\text { The } \\
\text { approximate } \\
\text { rollover } \\
\text { point }\left(\mathrm{m}^{2}\right)\end{array}$ \\
\hline This study & 6727 & 54.6 & 30 & 556381 & 8122 & 2.72 & 340 \\
Xu et al. (2014) & 7985 & 44.6 & 69 & 397408 & 5588 & 2.47 & 500 \\
Li et al. (2014) & 3896 & 34.2 & 306 & 525126 & 8789 & 2.51 & 1140 \\
Dai et al. (2011) & 576 & 30.9 & 714 & 2142126 & 53713 & 2.25 & 3850 \\
\hline
\end{tabular}



Figure 5. Comparing our inventory with the landslide initiation point inventory by Gorum et al. (2011) and the polygon-based inventory by Dai et al. (2011) for a small part of the area.

ter the earthquake provided better resolution and lower cloud cover than the satellite images used by the other two studies. The other two studies ignored many small landslides because they had to map the entire earthquake-affected area, while we devoted our time to landslide mapping for this smaller area. Dai et al. (2011) also merged several individual landslides into larger polygons (Fig. 5).

For a more detailed comparison between the observed landslide sizes of the different Wenchuan inventories, we have utilized the polygon-based Wenchuan inventories provided by Xu et al. (2014), Li et al. (2014), and Dai et al. (2011). Since these inventories cover a much larger landslide-affected area, we have extracted the landslides located inside our study area. The inventory from Gorum et al. (2011) could not be used since it only contained points, and no polygons.

We have analysed the frequency-area distribution (FAD) of landslide areas and observed the power-law scaling (e.g. Guzzetti et al., 2002; Hovius et al., 1997, 2000; Mala-

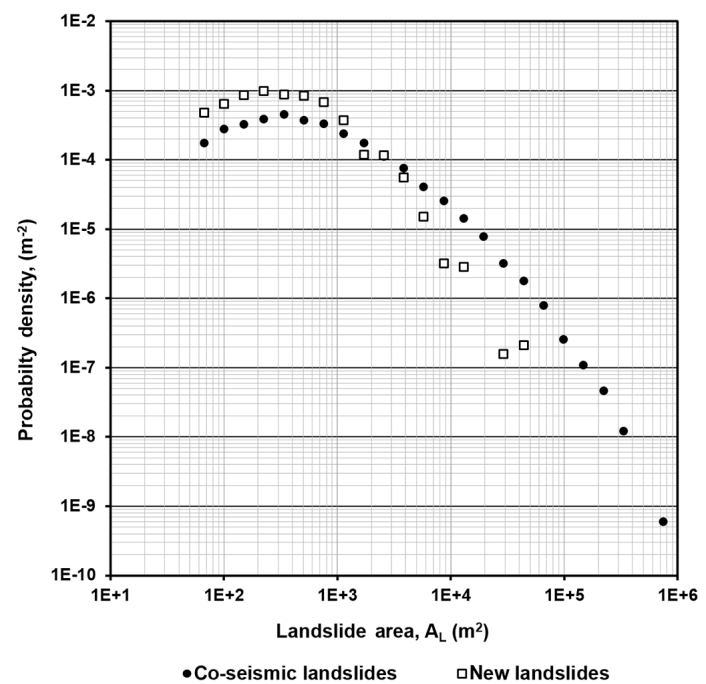

Figure 6. The frequency-area distributions (FAD) of the different co-seismic landslide inventories collected for the study area.

mud et al., 2004; Stark and Hovius, 2001) in all inventories (Fig. 6). In other words, we have observed an increasing trend in the number of the landslides from large to medium following a power-law. For each inventory, the slope of the FAD, which is called as the power-law exponent $(\beta)$, was calculated based on the method suggested by Clauset et al. (2009). The obtained $\beta$ values change from 2.4 to 2.7 (Table 5), which is consistent with the literature that points out an interval having a central tendency around 2.3-2.5 (Stark and Guzzetti, 2009; Van Den Eeckhaut et al., 2007). Towards the tail of the power-law, where we have fewer large landslides, the FADs of the inventories follow a similar line. The position of the power-law tail is assumed as the manifestation of landslide magnitude (Malamud et al., 2004). Although we are analysing different inventories with a varying completeness level, illustrated by different rollover points and distributions of the smaller landslides, all inventories show similar magnitudes. This observation supports the landslide event quantification theory of Malamud et al. (2004). 


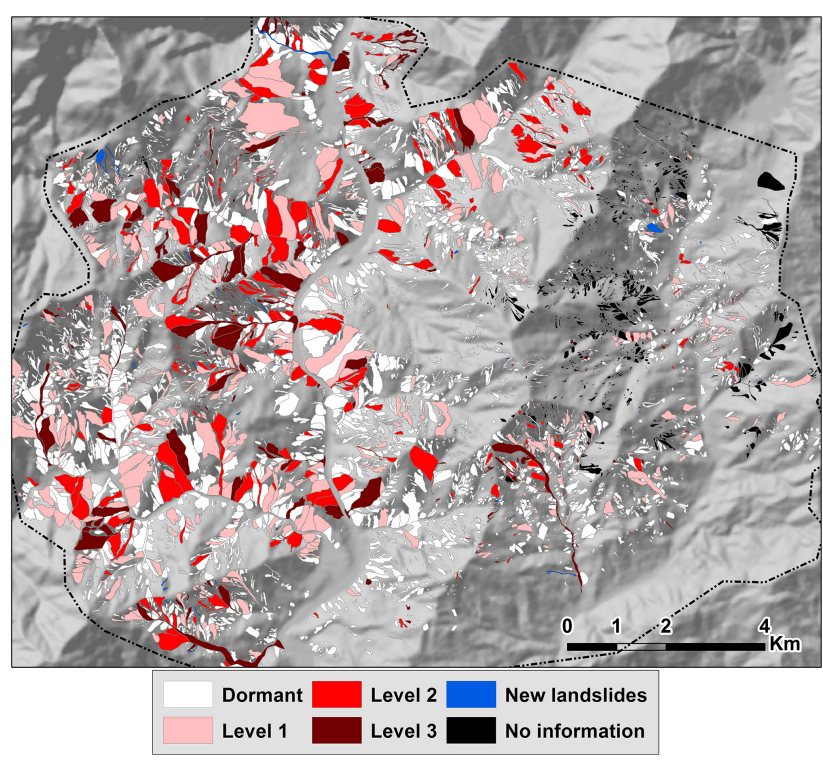

Figure 7. Landslide inventory map based on the image taken in February 2009, reflecting the state of activity after the rainy season of 2008.

In all inventories, we have also observed a divergence from the power-law distribution for the small landslides. The frequency of landslide areas begins to decrease after a certain size and follows a positive power-law decay, a phenomenon referred to as rollover (Stark and Hovius, 2001). Since the frequency of landslide areas keeps increasing up to the rollover point, the rollover point is considered as the most frequently occurring landslide area in the inventory (e.g. Parker et al., 2015). In this regard, we have evaluated the relative completeness level of the inventories. Since the inventory of Dai et al. (2011) is one of the pioneer inventories generated soon after the Wenchuan event, it has a relatively lower resolution. The average landslide area of this inventory is around $53000 \mathrm{~m}^{2}$, while for the other inventories this value changes between 5500 and $8000 \mathrm{~m}^{2}$ (Table 5). Therefore, in the inventory from Dai et al. (2011) the rollover point is observed around $3850 \mathrm{~m}^{2}$, which is the largest rollover point among all the Wenchuan inventories. On the other hand, our inventory gives the lowest rollover point and it is nearly complete up to around $340 \mathrm{~m}^{2}$. This finding can be interpreted as the relatively higher completeness level of our inventory. The inventory of $\mathrm{Xu}$ et al. (2014) shows a similar completeness level since our product and their product are nearly complete up to $500 \mathrm{~m}^{2}$. Furthermore, our inventory gives relatively smoother positive power-law decay than the inventory of $\mathrm{Xu}$ et al. (2014). This indicates that our inventory includes a higher number of smaller landslides as compared to the inventory from $\mathrm{Xu}$ et al. (2014). The rollover point for the inventory of Li et al. (2014) is around $1140 \mathrm{~m}^{2}$, and it can be considered as less complete compared to our inventory and the one by $\mathrm{Xu}$ et al. (2014).

\subsection{Post-seismic landslide inventories}

In the years after the earthquake, large numbers of mass movements were induced by rain storms, whereas many others were slowly covered by vegetation regrowth. Using the available satellite images (Table 1), four new landslide inventories were generated.

An inventory for 2009 was made using a Spot 5 image from February 2009, with a spatial resolution of $2.5 \mathrm{~m}$. The inventory reflects the state of activity after the rainy season of 2008, during which a large number of debris flows were formed. The landslide inventory map is shown in Fig. 7. Due to cloud cover in the 2008 images, part of the landslide changes in the eastern part could not be identified. Even though there had been significant rainfall events in the monsoon of 2008, the number of active landslides was reduced to 967 including an additional 83 new landslides. Most of the active landslides (69\%) were debris flows. Except for the areas covered by clouds in the 2008 images, $13 \%$ of the earthquake-triggered landslides were reactivated.

We were not able to find suitable images for 2010; therefore, we decided to make a new inventory every two years after the earthquake. The next landslide inventory was made based on a Worldview Image from April 2011 with $1 \mathrm{~m}$ spatial resolution. The image was cloud free except for a small area in the eastern part. In this inventory $28 \%$ of the pre-existing landslides were active during this period, and the number of active landslides has increased significantly to $2633,66 \%$ of which are debris flows. As can be seen from Fig. 8, this inventory is almost complete (44 no-information landslides) for the entire area. There were also 569 new landslides mapped between 2009 and 2011. This indicates that between February 2009 and April 2011 there was one or more extreme rainfall events, which will be further discussed in the next section.

A Pleiades image from April 2013, with a spatial resolution of $0.5 \mathrm{~m}$, was used to map the next landslide inventory. However, due to the different image size, only $69 \%$ of the interpretation area could be mapped in 2013 (Fig. 9). It is obvious that the activity levels in 2013 were much lower than in the previous periods. Except for the areas outside the image boundary, only $3 \%$ of the pre-existing landslides were active and $88 \%$ of them were identified with a landslide activity level 1 (dormant).

The last landslide inventory map was made using a Spot 6 image with a spatial resolution of $1.5 \mathrm{~m}$ from April 2015. This image covers most of the study area except for a small part in the north (Fig. 10). Only 66 active landslides were identified in the image, of which only two were new landslides. Less than $1 \%$ of the pre-existing landslides were active. Compared with the images of the earlier period, the vegetation cover on landslides in 2015 was significantly higher.

After the earthquake, from 2008 to April 2015, the number of landslides (including the dormant landslides) in the study area increased by 660 to a total of 7387 . The total landslide 


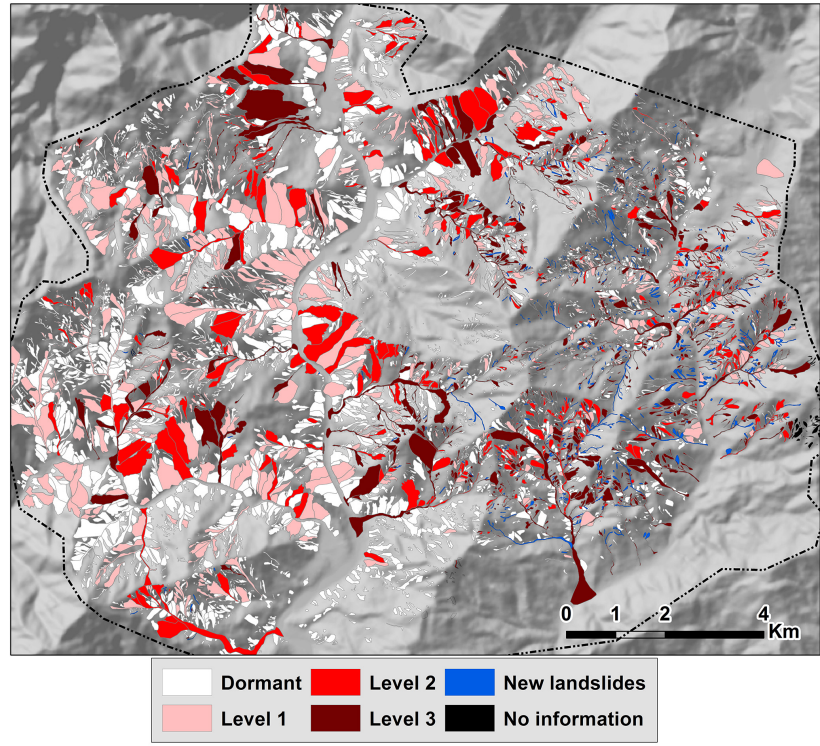

Figure 8. Landslide inventory map based on the image taken in April 2011, reflecting the state of activity after the rainy seasons of 2009 and 2010.

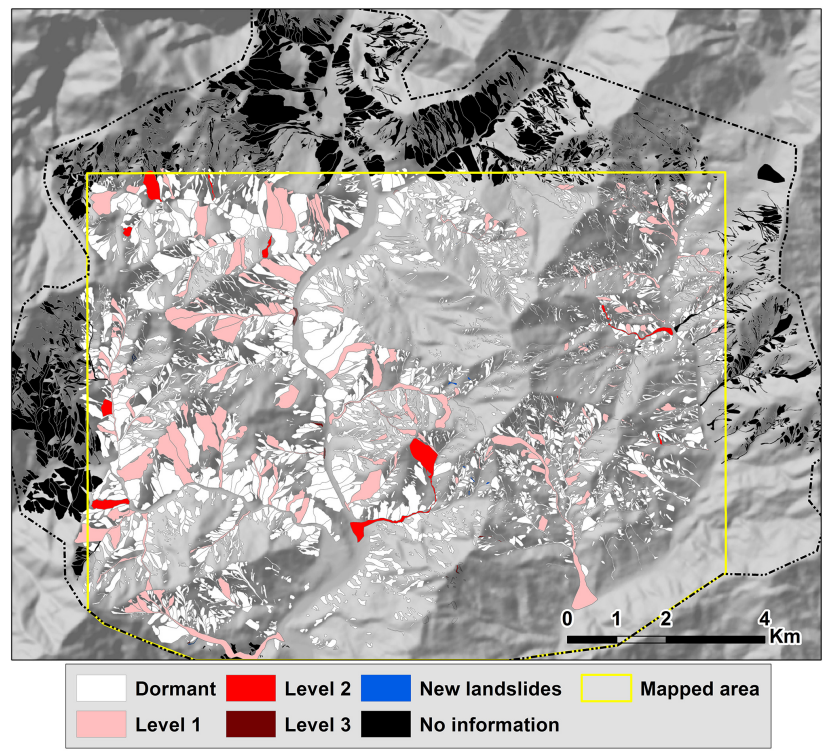

Figure 9. Landslide inventory map based on the image taken in April 2013, reflecting the state of activity after the rainy seasons of 2011 and 2012. The actual mapped area was limited within the yellow polygon due to the smaller area covered by the available Pleiades image.

area increased from 54.6 to $58.3 \mathrm{~km}^{2}$. This indicates that the landslide activity in the post-earthquake period was not restricted to the co-seismic landslide area only. This is important to consider when making post-earthquake reconstruction planning in other mountainous environments. Landslide activity evolved in different ways. The first type of reactivation

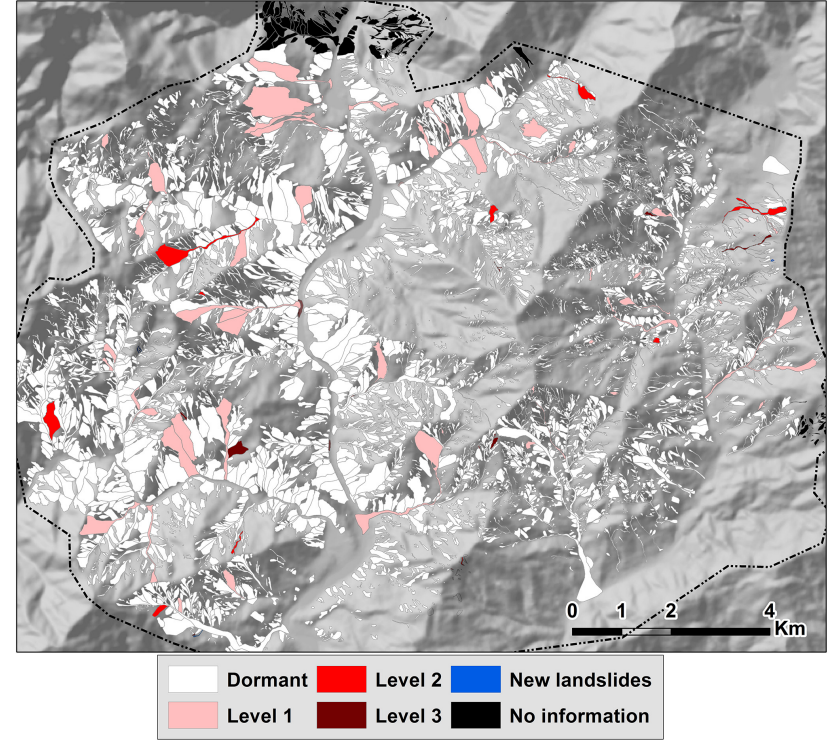

Figure 10. Landslide inventory map based on the image taken in April 2015, reflecting the state of activity after the rainy seasons of 2013 and 2014.

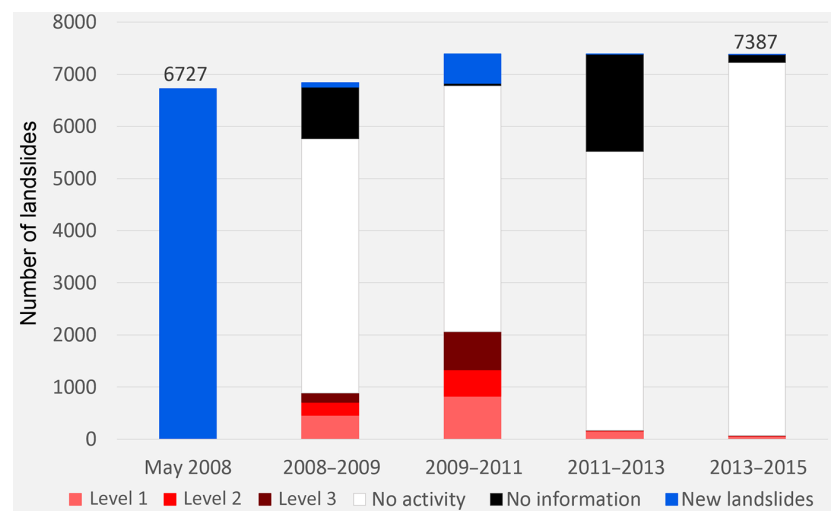

Figure 11. Activity levels of the five landslide inventories.

observed was from slide-type movements of the bare surfaces of co-seismic landslides. Also flow-type movement caused by run-off erosion in the landslide deposits of the pre-existing landslides, with deposition either occurring on top of earlier debris flow materials, or covering new areas. This was considered as the main cause for the enlargement of co-seismic landslides. The third observed mechanism was a retrogressive activity of the scarps in the initiation area. Of the total of 6727 co-seismic landslides, 2221 had one or more phases of reactivation after they were triggered by the earthquake until April 2015. The most frequent post-earthquake landslide type is flow, accounting for $66 \%$ of all the active landslides in the post-earthquake inventories. Table 6 summarizes the statistics of the four post-earthquake landslide inventories.

In general, the landslide activity decreased considerably from May 2008 to April 2015, with the total of active land- 
slides reducing from 6727 co-seismic landslides to 66 active landslides in 2015. After the 2010 monsoon season, the activity of the post-earthquake landslides dropped considerably and most of the active landslides were marked with activity level 1 (Fig. 11). Table 7 shows details of the landslide activity changes for the various inventories. Between the inventories of 2009 and 2011, at least 1834 landslides had an increased activity level. About half of the active landslides in the 2011 inventory are co-seismic, which were dormant in the 2009 inventory, and $39 \%$ of the active landslides in the inventory of 2009 became dormant in 2011. From April 2011 to April 2013, 66\% of the active landslides in the inventory of 2011 became dormant in the inventory of 2013. Of the active landslides in 2013, $65 \%$ were active pre-existing landslides with a higher activity class level in 2011. From April 2013 to April 2015, $90 \%$ of the active landslides in the inventory of 2013 became dormant, $44 \%$ of the active landslides in $2015 \mathrm{kept}$ the same activity level as in 2013, and $46 \%$ of the active landslides occurred on pre-existing landslides that were dormant in 2013. We can conclude from this analysis that the pattern of active landslides changes constantly over time. It is not possible to predict after the earthquake which landslides will remain active over the next decade since this pattern changes constantly, most probably related to the specific variation of rainfall intensity during rainstorms in the post-earthquake period.

Most of the new landslides occurred during the period of 2009-2011. The most frequent landslide type for the new landslides was slide (60.4\%), followed by flow (36\%) and fall $(3.6 \%)$. The average area of the new landslides is $1339 \mathrm{~m}^{2}$, with a range from 34 to $31356 \mathrm{~m}^{2}$. The large new landslides are mainly debris flows with long runout distances. Overall the new landslides are mainly small and medium-sized landslides: $90 \%$ of the new landslides are less than $3023 \mathrm{~m}^{2}$.

When we compare the number of 66 active landslides in the inventory of 2015 with the 132 landslides recorded from 1961 to 2005 (Varnes, 1978) in the whole $3936 \mathrm{~km}^{2}$ Wenchuan county, the frequency of the landslide occurrence has increased significantly after the earthquake, and it is still not back to the pre-earthquake levels. It can be further observed that the increase in post-earthquake landslides both in number and in area were 8.9 and $6.8 \%$ respectively, which is much lower than observed in Taiwan after the Chi-Chi earthquake $(42.8 \%$ increase in area within 2 years according to Lin et al., 2006). The landslide increment after the Chi-Chi earthquake could be caused by its location in relation to the path of typhoons, as the areas were affected several times by rainfall events with more than $100 \mathrm{~mm} \mathrm{~h}^{-1}$ precipitation intensity. In the Wenchuan area, the recorded rainfall intensity and cumulative rainfall are much lower (Table 8). Also, the lithology in both areas is completely different, with volcanic rocks underlying most of the Wenchuan area, while sedimentary and metamorphic rocks are most common in the area affected by the Chi-Chi earthquake (Lin et al., 2006).
Table 6. Statistics of post-earthquake landslide inventories. ${ }^{1}$ The total number of landslides in each inventory including those without information (which are either located in cloud-covered areas, or areas outside of the image boundaries). ${ }^{2}$ Total number of landslides in each inventory, excluding those without information and those that are dormant (activity level 0).

\begin{tabular}{|c|c|c|c|c|}
\hline Activity level & Fall & Slide & Flow & $\begin{array}{r}\text { Sum by } \\
\text { activity } \\
\text { level }\end{array}$ \\
\hline \multicolumn{5}{|c|}{ The inventory of 2009} \\
\hline No information & & - & & 988 \\
\hline 0 & & -4855 & & \\
\hline 1 & 8 & 91 & 353 & 452 \\
\hline 2 & 2 & 73 & 175 & 250 \\
\hline 3 & 0 & 70 & 112 & 182 \\
\hline New landslide & 1 & 51 & 31 & 83 \\
\hline Sum by movement type & 11 & 285 & 671 & $\begin{array}{r}6810^{1} \\
967^{2}\end{array}$ \\
\hline \multicolumn{5}{|c|}{ The inventory of 2011} \\
\hline No information & & - & & 44 \\
\hline 0 & & - & & 4718 \\
\hline 1 & 7 & 182 & 622 & 811 \\
\hline 2 & 2 & 180 & 323 & 505 \\
\hline 3 & 4 & 292 & 436 & 732 \\
\hline New landslide & 1 & 215 & 353 & 569 \\
\hline Sum by movement type & 14 & 869 & 1734 & $\begin{array}{l}7379^{1} \\
2617^{2}\end{array}$ \\
\hline \multicolumn{5}{|c|}{ The inventory of 2013} \\
\hline No information & & - & & 1862 \\
\hline 0 & & -5348 & & \\
\hline 1 & 2 & 3 & 149 & 154 \\
\hline 2 & 0 & 0 & 12 & 12 \\
\hline 3 & 0 & 0 & 3 & 3 \\
\hline New landslide & 0 & 4 & 2 & 6 \\
\hline Sum by movement type & 2 & 7 & 166 & $\begin{array}{r}7385^{1} \\
175^{2}\end{array}$ \\
\hline \multicolumn{5}{|c|}{ The inventory of 2015} \\
\hline No information & & - & & 150 \\
\hline 0 & & - & & 7171 \\
\hline 1 & 0 & 3 & 41 & 44 \\
\hline 2 & 0 & 1 & 9 & 10 \\
\hline 3 & 0 & 3 & 7 & 10 \\
\hline New landslide & 0 & 0 & 2 & 2 \\
\hline Sum by movement type & 0 & 7 & 59 & $\begin{array}{r}7387^{1} \\
66^{2}\end{array}$ \\
\hline
\end{tabular}

\subsection{Triggering factor}

The large differences in landslide activity that were observed between the post-earthquake landslide inventories, especially the increase in activity observed in the 2011 inventory, were 
Table 7. Changes in landslide activity level of the consecutive years. ${ }^{1}$ Total number of landslides with increased activity level compared with the previous period. ${ }^{2}$ Number of landslides that became dormant. ${ }^{3}$ Number of landslides with decreased activity level, excluding dormant. ${ }^{4}$ Number of landslides with the same activity level as the previous period. ${ }^{5}$ Number of landslides that remain dormant in both inventories. The number mismatches were caused by small landslides that were ignored by ArcMap software during rastering of the inventories to do this analysis.

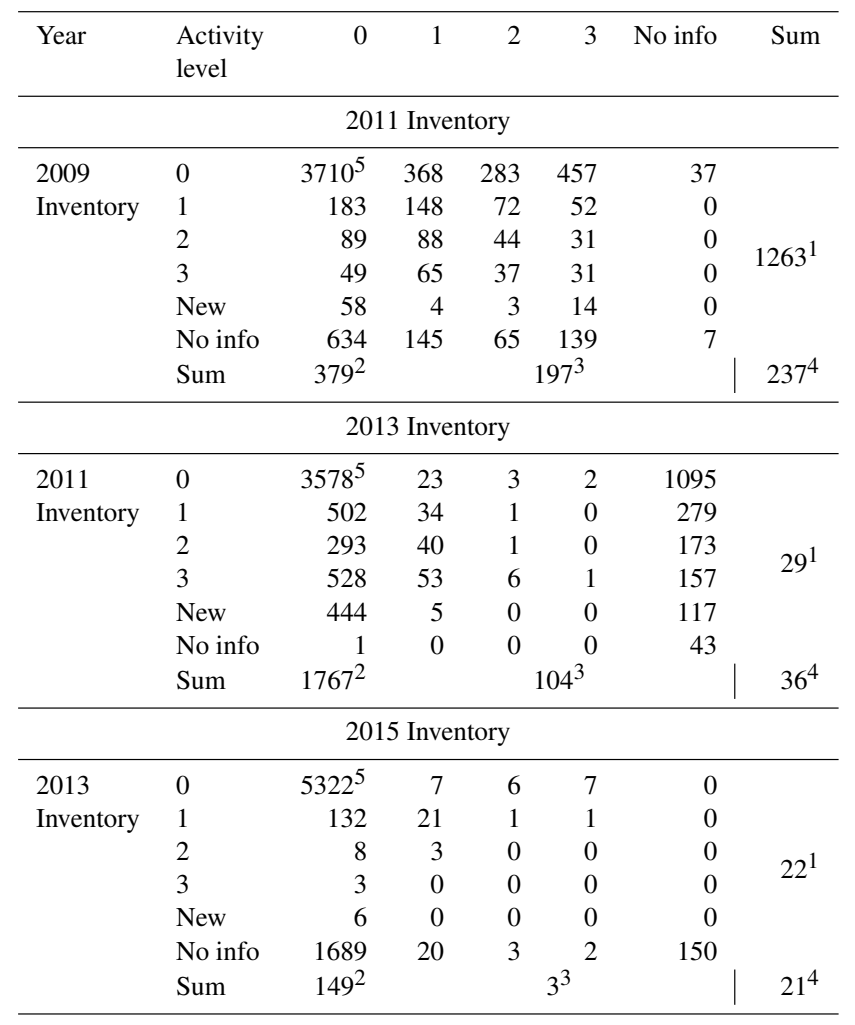

expected to be caused by differences in extreme rainfall events.

Previous works (Lin et al., 2006; Zhou et al., 2013) have indicated that the magnitude and scale of the post-seismic landslide activity are related to the spatial distribution and intensity of rainfall events. Unfortunately, there are very few rain gauges in the direct surroundings of the study area that were operational from 2008 onwards. After a large number of landslides were triggered by the storm in 2010, several rain gauges were installed in five catchments that were considered highly dangerous. From the 18 available rain gauges and literature study, we analysed the maximum intensity, duration, and accumulated precipitation of the largest rainfall event of each year as indicators for the importance of the monsoon of that year in landslide reactivation. The rainfall data of the largest rainfall events from 2011 to 2015 are average values calculated from several rain gauges distributed across the area (Table 8).
Table 8. Maximum rainfall intensity, duration, and accumulated rainfall of the largest rainfall events of each year. The sources of rainfall data are indicated in Table 1.

\begin{tabular}{llrrr}
\hline $\begin{array}{l}\text { Related } \\
\text { inventory }\end{array}$ & Date & $\begin{array}{r}\text { Peak } \\
\text { intensity } \\
\left(\mathrm{mm} \mathrm{h}^{-1}\right)\end{array}$ & $\begin{array}{r}\text { Accumulated } \\
\text { rainfall } \\
(\mathrm{mm})\end{array}$ & $\begin{array}{r}\text { Duration } \\
(\mathrm{h})\end{array}$ \\
\hline 2009 & 23 Sep 2008 & 60 & 347 & 10 \\
2011 & 17 Jul 2009 & 70 & 219 & 6 \\
& 13 Aug 2010 & 75 & 229 & 17 \\
2013 & 29 Jul 2011 & 54 & 150 & 20 \\
& 18 Aug 2012 & 39.5 & 117 & 6 \\
2015 & 10 Jul 2013 & 64 & 108.5 & 6 \\
& 10 Apr 2014 & 53 & 53 & 1 \\
\hline
\end{tabular}

The two largest rainfall events occurred during the monsoons of 2009 and 2010. They reactivated a considerable number of landslides, as can be observed from the inventory of 2011. The maximum rainfall intensity and accumulated precipitation of the monsoon of 2008 were similar to those from 2011 to 2014. However, in the 2009 inventory there were more active landslides than in the inventories of 2013 and 2015. This is due to the fact that most of the landslide scarps had not regrown vegetation yet in the months following the earthquake. In 2011 many more landslides regrew vegetation, and the same magnitude of rainfall reactivated many fewer landslides than in 2008. Also the availability of loose materials in the initiation zone was likely much less in 2011 as compared to 2008 due to landslide activity during the period in between. The loose materials were transported downstream as debris flows (Fig. 12). The vegetation cover class on the earthquake-triggered landslides in 2008 was 3 (> two-thirds bare). In the inventory of 2009, this had changed to 2 , and then 3 again in the inventory of 2011 due to massive landslide reactivation. The value was lowered to 1 ( $<$ one-third bare) in the inventory of 2015.

The pattern of reactivation of landslides can also be related to different spatial distributions of the rainfall events that occurred in the period in between two dates for which landslide inventories are available. However, the available rainfall data did not allow us to generate rainfall distribution maps for the various landslide events. This should be investigated further in the future.

\subsection{Controlling factors}

The relation between landslide activity changes and topographic factors, such as slope direction and slope angle, was also analysed. The relation with lithology was also analysed. We calculated the ratio of the area of active landslides to the total landslide area within each factor class. The results indicate that aspect is not a significant factor in determining the presence of active post-seismic landslides. In the areas with granite, diorite, and sandstone the percentages of active landslides were 41,28 , and $43 \%$ respectively. The areas with 


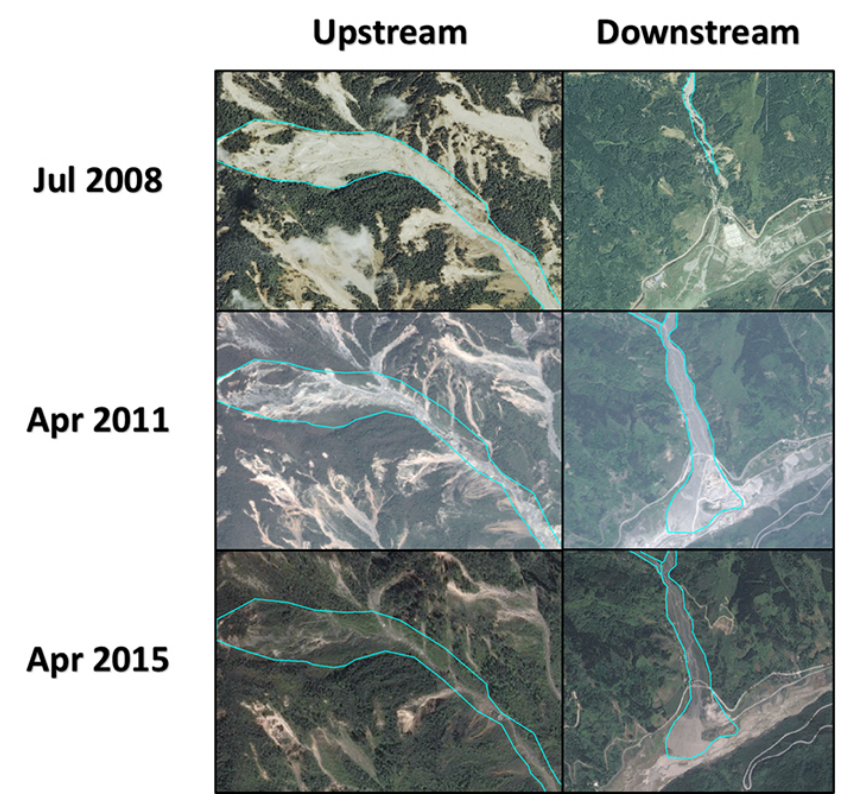

Figure 12. Examples of changes in landslide activity in the source and deposition areas of a typical debris flow gulley. In 2008 the loose materials produced by this co-seismic landslide were still located in the upslope part of the valley. After three rainy seasons, debris flows and erosion transported the materials to the downstream area. In 2015, most of the upstream area was covered by vegetation again, and debris flow activity in the downstream part had reduced considerably.

other lithology types were too small in size to make a proper analysis. A comparison of active landslide percentages for different slope classes showed that slopes steeper than $20^{\circ}$ had a much higher degree of reactivation. However, lower slope angles occurring in the channels and alluvial fans also had a very high percentage of landslide activity, caused by the occurrence of debris flow deposits.

There is also an important difference in active landslide percentage when comparing the western (Yingxiu) and the eastern part (Longchi). The Yingxiu area had much more and larger-sized co-seismic landslides than the Longchi area. However, in the 2011 inventory, $46 \%$ of the landslides in the eastern part were active, which is $22 \%$ more than the western part. This was caused by the large amount of new landslides in the eastern part, which contained $83 \%$ of all new landslides. This phenomenon indicates that the effect of the earthquake was much stronger in the western part, which had more rugged topography where the weathering soil mantle was removed by co-seismic landslides. This was different in the eastern area, where there were less co-seismic and more post-seismic landslides. Some slopes were loosened by the earthquake but did not fail immediately after the earthquake, and in later years landslides were triggered by large amounts of rainfall on those unstable slopes.

\section{Discussion and conclusions}

We analysed changes in landslide activity in a period of seven years after the 2008 Wenchuan earthquake, with five multitemporal landslide inventories, which we interpreted stereoscopically from high-resolution images, followed by field investigation. The results show that most of the post-seismic landslide activities were concentrated within the first 3 years following the earthquake. The landslide activity decreased considerably from May 2008 to April 2015, from 6727 coseismic landslides to 66 active landslides in 2015. After the 2010 monsoon season, the activity of the post-earthquake landslides dropped considerably and most of the active landslides became dormant. Of the total of 6727 co-seismic landslides, $2221 \mathrm{had}$ one or more phases of reactivation. Apart from the reactivation of co-seismic landslides, 660 new landslides also occurred after 2008. This indicates that the landslide activity in the post-earthquake period was not restricted to the co-seismic landslide area only. This is important to consider when planning post-earthquake reconstruction in other mountainous environments.

In the digital stereo image interpretation we did not adopt a minimum threshold for landslide area. When comparing our results with other landslide inventories in this area through frequency-area distribution (FAD), our inventory shows the highest level of completeness, the highest number of small landslides, and also the highest total landslide area. However, the inventory also shows a lower total landslide volume calculated from the empirical method presented by Guzzetti et al. (2009). This might be an indication that the number and area of the landslides reported so far for the whole area hit by the earthquake may be under estimated and the volume could be overestimated.

In this study we were able to devote more time to this local scale area to make a detailed landslide mapping than the previous studies, which were mapping the entire earthquakeaffected area. We were also able to collect more highresolution remote sensing image data than previous studies. The use of digital stereo image interpretation was also important for mapping landslide boundaries and making landslide classifications. However, the mapping process was much more time consuming compared to semi-automatic image classification or monoscopic image interpretation procedures. The mapping process also requires specific skills, and different people can produce different image interpretation results. We included an extensive procedure for double checking the mapped landslides by different interpreters in order to ensure consistency of the inventory. The largest differences in interpretation occurred in areas with very steep and complex slopes, where the terrain could not be represented well due to the relatively poor quality of the available DEM. When determining the activities of the postearthquake landslides, we carefully compared the images from different periods, looking for differences in the image characteristics. This gave us more detailed results compared 
with common landslide mapping methods that define landslides activity directly from vegetation cover, and it allowed us to distinguish the actual active landslide from bare dormant landslides.

Though the landslide activity reduced after April 2011, extreme rainfall events could still trigger large numbers of landslides. After the extreme rainstorm in August 2010, there were not any other extreme rainfall events in the area up to 2015. However, we can observe in recent images and fieldwork that there are still large volumes of loose material on the slopes and in the upper parts of the catchments. Though these areas are mostly covered by vegetation re-growth, they could be activated by extreme rainfall events. In the coming years and decade the chance of landslide re-activation will be determined by the speed of vegetation re-growth, the available volume of loose material, and the occurrence of extreme rainfall events. The limited rainfall data that are available show that the rainfall threshold to trigger landslides is rising, leading to less landslides in the last two inventories. However, we lack enough rainfall data to do a comprehensive rainfall threshold analysis. We were also only able to estimate landslide volumes using an empirical method. The actual volume of landslides in the area is unknown due to the lack of a high-resolution pre-earthquake DEM. It is still hard to make a prediction of how long it will take before landslide activity is back at pre-earthquake levels. Monitoring of landslide activities over a longer period is required.

During our mapping process we have noticed that the large co-seismic landslides (like the one in Fig. 12) are very likely to generate major debris flows in the future. Of the co-seismic landslides with an area larger than $20000 \mathrm{~m}^{2}, 11$ out of 18 had the highest level of activity recorded, and 6 of them had the second highest level in the post-seismic landslide inventories. All the recorded large debris flows in the area were initiated from these 11 large landslides. In some of the downstream parts, extensive debris flow mitigation works have been carried out, although some of these have been destroyed or almost covered by debris. It is recommended to monitor the activity of these large landslides, and in some cases early warning systems have already been installed.

The main sources of errors in the landslide inventory mapping are related to the image rectification quality, which varied for the different types of images used; the different resolution of the images (in particular the Spot 5 image); and the skill and experience of the interpreters in mapping landslides and classifying the landslide activity. The image wraps of the Spot 5 image in steep terrain affected 180 landslides, and the low resolution of this image roughly affected 300400 landslides. The uncertainty of the landslide activity level is largely based on the interpreters' experience and judgement based on observing images. The best way to minimize these errors is to have good-quality images of every single year since the earthquake. However, for our study area this is not possible since high-resolution images from 2010 and 2012 could not be found in any image database. Inter- preters' skill and experience with the mapping area are also important. The uncertainty was reduced by comparing the interpretations carried out by different investigators.

We recommend continuing to monitor the landslides through image analysis. In addition to remote sensing images, multi-temporal DEMs generated from lidar data and UAV photogrammetry can be useful for monitoring and quantifying the changes. Rainfall data with good spatial and temporal resolution, essential for designing an early warning system, should also be collected to make a comprehensive rainfall threshold analysis.

We can conclude from this analysis that the pattern of active landslides constantly changes over time. It is not possible to predict after the earthquake which landslides will remain active over the next decade since this pattern changes constantly, most probably related to the specific variation of rainfall intensity during rainstorms in the post-earthquake period.

Acknowledgements. The authors would like to thank the State Key Laboratory for Geohazard Prevention and Environmental Protection (SKLGP), Chengdu, China, for providing data and support with the fieldwork. We would like to thank the EU FP7 Copernicus project INCREO (http://www.increo-fp7.eu/) for providing some of the satellite data. We thank MSc students Yu Yang, Yi Wang, and Chenhao Xia in SKLGP for helping us to prepare the landslide inventories. We also thank Theo Van Asch for giving useful advice on our research.

Edited by: K.-T. Chang

Reviewed by: two anonymous referees

\section{References}

Chang, K.-J., Taboada, A., Chan, Y.-C., and Dominguez, S.: Postseismic surface processes in the Jiufengershan landslide area, 1999 Chi-Chi earthquake epicentral zone, Taiwan, Eng. Geol., 86, 102-117, 2006.

Cheng, J. D., Huang, Y. C., Wu, H. L., Yeh, J. L., and Chang, C. H.: Hydrometeorological and landuse attributes of debris flows and debris floods during typhoon Toraji, July 29-30, 2001 in central Taiwan, J. Hydrol., 306, 161-173, 2005.

Clauset, A., Shalizi, C. R., and Newman, M. E.: Power-law distributions in empirical data, SIAM Rev., 51, 661-703, 2009.

Cruden, D. and Varnes, D.: Landslide types and processes, USGS, available at: http://pubs.usgs.gov/fs/2004/3072/pdf/ fs2004-3072.pdf (last access: December 2016), 1996.

Dai, F. C., Xu, C., Yao, X., Xu, L., Tu, X. B., and Gong, Q. M.: Spatial distribution of landslides triggered by the 2008 Ms 8.0 Wenchuan earthquake, China, J. Asian Earth Sci., 40, 883-895, 2011.

Dong, J.-J., Li, Y.-S., Kuo, C.-Y., Sung, R.-T., Li, M.-H., Lee, C.T., Chen, C.-C., and Lee, W.-R.: The formation and breach of a short-lived landslide dam at Hsiaolin village, Taiwan - part I: Post-event reconstruction of dam geometry, Eng. Geol., 123, 4059, 2011. 
Fan, J. C., Liu, C. H., Wu, M. F., and Yu, S. K.: Determination of critical rainfall thresholds for debris-flow occurrence in central Taiwan and their revision after the 1999 Chi-Chi great earthquake, in: Debris-Flow Hazards Mitigation: Mechanics, Prediction, and Assessment, Vol. 1-2, Millpress Science Publishers, Rotterdam, 103-114, 2003.

Fan, X., van Westen, C. J., Korup, O., Gorum, T., Xu, Q., Dai, F., Huang, R., and Wang, G.: Transient water and sediment storage of the decaying landslide dams induced by the 2008 Wenchuan earthquake, China, Geomorphology, 171-172, 58-68, 2012.

Gorum, T., Fan, X., van Westen, C. J., Huang, R. Q., Xu, Q., Tang, C., and Wang, G.: Distribution pattern of earthquake-induced landslides triggered by the 12 May 2008 Wenchuan earthquake, Geomorphology, 133, 152-167, 2011.

Guzzetti, F., Malamud, B. D., Turcotte, D. L., and Reichenbach, P.: Power-law correlations of landslide areas in central Italy, Earth Planet. Sc. Lett., 195, 169-183, 2002.

Guzzetti, F., Ardizzone, F., Cardinali, M., Rossi, M., and Valigi, D.: Landslide volumes and landslide mobilization rates in Umbria, central Italy, Earth Planet. Sc. Lett., 279, 222-229, 2009.

Hovius, N., Stark, C. P., and Allen, P. A.: Sediment flux from a mountain belt derived by landslide mapping, Geology, 25, 231234, 1997.

Hovius, N., Stark, C. P., Hao, C., and Jiun, L.: Supply and removal of sediment in a landslide-dominated mountain belt: Central Range, Taiwan, J. Geol., 108, 73-89, 2000.

Hovius, N., Meunier, P., Lin, C.-W., Chen, H., Chen, Y.-G., Dadson, S., Horng, M.-J., and Lines, M.: Prolonged seismically induced erosion and the mass balance of a large earthquake, Earth Planet. Sc. Lett., 304, 347-355, 2011.

Huang, R. and Fan, X.: The landslide story, Nat. Geosci., 6, 325326, 2013.

Li, G., West, A. J., Densmore, A. L., Jin, Z., Parker, R. N., and Hilton, R. G.: Seismic mountain building: Landslides associated with the 2008 Wenchuan earthquake in the context of a generalized model for earthquake volume balance, Geochem. Geophy. Geosy., 15, 833-844, 2014.

Lin, C.-W., Liu, S.-H., Lee, S.-Y., and Liu, C.-C.: Impacts of the Chi-Chi earthquake on subsequent rainfall-induced landslides in central Taiwan, Eng. Geol., 86, 87-101, 2006.

Lin, G.-W., Chen, H., Hovius, N., Horng, M.-J., Dadson, S., Meunier, P., and Lines, M.: Effects of earthquake and cyclone sequencing on landsliding and fluvial sediment transfer in a mountain catchment, Earth Surf. Proc. Land., 33, 1354-1373, 2008.

Liu, Y., Liu, R., and Ge, Q.: Evaluating the vegetation destruction and recovery of Wenchuan earthquake using MODIS data, Nat. Hazards, 54, 851-862, 2010.

Lu, T., Zeng, H., Luo, Y., Wang, Q., Shi, F., Sun, G., Wu, Y., and Wu, N.: Monitoring vegetation recovery after China's May 2008 Wenchuan earthquake using Landsat TM time-series data: a case study in Mao County, Ecol. Res., 27, 955-966, 2012.

Ma, y., Yu, B., Wu, Y., Zhang, J., and Qi, X.: Research on the Disaster of Debris Flow of Bayi Gully, Longchi, Dujiangyan, Sichuan on August 13, 2010, J. Sichuan Univers., 43, 1009-3087, 2011.

Malamud, B. D., Turcotte, D. L., Guzzetti, F., and Reichenbach, P.: Landslide inventories and their statistical properties, Earth Surf. Proc. Land., 29, 687-711, 2004.

Ni, H. Y., Zheng, W. M., Tie, Y. B., Su, P. C., Tang, Y. Q., Xu, R. G., Wang, D. W., and Chen, X. Y.: Formation and characteristics of post-earthquake debris flow: a case study from Wenjia gully in Mianzhu, Sichuan, SW China, Nat. Hazards, 61, 317-335, 2011. Parker, R. N., Hancox, G. T., Petley, D. N., Massey, C. I., Densmore, A. L., and Rosser, N. J.: Spatial distributions of earthquakeinduced landslides and hillslope preconditioning in the northwest South Island, New Zealand, Earth Surf. Dynam., 3, 501-525, doi:10.5194/esurf-3-501-2015, 2015.

Shieh, C.-L., Chen, Y. S., Tsai, Y. J., and Wu, J. H.: Variability in rainfall threshold for debris flow after the Chi-Chi earthquake in central Taiwan, China, Int. J. Sediment Res., 24, 177-188, 2009.

Shou, K. J., Hong, C. Y., Wu, C. C., Hsu, H. Y., Fei, L. Y., Lee, J. F., and Wei, C. Y.: Spatial and temporal analysis of landslides in Central Taiwan after 1999 Chi-Chi earthquake, Eng. Geol., 123, 122-128, 2011a.

Shou, K. J., Wu, C. C., Fei, L. Y., Lee, J. F., and Wei, C. Y.: Dynamic environment in the Ta-Chia River watershed after the 1999 Taiwan Chi-Chi earthquake, Geomorphology, 133, 190-198, 2011 b.

Soeters, R. and van Westen, C. J.: Slope instability recognition, analysis and zonation: Landslides, investigation and mitigation, Special Report, Transportation Research Board, National Research Council, 129-177, https://www.researchgate.net/publication/209803184_Slope_ instability_Recognition_analysis_and_zonation (last access: December 2016), 1996.

Stark, C. P. and Guzzetti, F.: Landslide rupture and the probability distribution of mobilized debris volumes, J. Geophys. Res.-Ea. Surf., 114, F00A02, doi:10.1029/2008JF001008, 2009.

Stark, C. P. and Hovius, N.: The characterization of landslide size distributions, Geophys. Res. Lett., 28, 1091-1094, 2001.

Tang, C. and Liang, J.: Case study on the 9.24 storm-triggered debrisflow in Beichuan, J. Eng. Geol., 1004-9665, 2008.

Tang, C., Rengers, N., van Asch, Th. W. J., Yang, Y. H., and Wang, G. F.: Triggering conditions and depositional characteristics of a disastrous debris flow event in Zhouqu city, Gansu Province, northwestern China, Nat. Hazards Earth Syst. Sci., 11, 29032912, doi:10.5194/nhess-11-2903-2011, 2011.

Tang, C., Zhu, J., Li, W. L., and Liang, J. T.: Rainfall-triggered debris flows following the Wenchuan earthquake, Bull. Eng. Geol. Environ., 68, 187-194, 2009.

Van Den Eeckhaut, M., Poesen, J., Govers, G., Verstraeten, G., and Demoulin, A.: Characteristics of the size distribution of recent and historical landslides in a populated hilly region, Earth Planet. Sc. Lett., 256, 588-603, 2007.

Varnes, D.: Slope movement types and processes, National Research Council, Transportation Research Board, USA, 1133, https://trid.trb.org/view.aspx?id=86168 (last access: December 2016), 1978.

Wang, M., Yang, W., Shi, P., Xu, C., and Liu, L.: Diagnosis of vegetation recovery in mountainous regions after the Wenchuan earthquake, IEEE J. Select. Top. Appl. Earth Obs. Rem. Sens., 7, 3029-3037, 2014.

Xu, C., Xu, X., Yao, X., and Dai, F.: Three (nearly) complete inventories of landslides triggered by the May 12, 2008 Wenchuan Mw 7.9 earthquake of China and their spatial distribution statistical analysis, Landslides, 11, 441-461, 2014.

Xu, Q., Zhang, S., Li, W. L., and van Asch, Th. W. J.: The 13 August 2010 catastrophic debris flows after the 2008 Wenchuan earthquake, China, Nat. Hazards Earth Syst. Sci., 12, 201-216, doi:10.5194/nhess-12-201-2012, 2012. 
You, Y., Liu, J., Chen, X., and Pan, H.: Debris flow formation conditions and optimal characteristics of drainage canal following Wenchuan earthquake, Environ. Earth Sci., 65, 1005-1012, 2011.

Zhang, H., Fan, J., and Liu, Q.: Predicting Volume and Runout of Single Gully Debris-Flow Using Hypsometric Integral Value in the Wenchuan Earthquake Area, in: Earthquake-Induced Landslides, Springer, 301-311, doi:10.1007/978-3-642-32238-9_31, 2013.
Zhou, W., Tang, C., and Zhou, C.-H.: Rainfall Patterns of Post-seismic Debris Flows in the Wenchuan Earthquake Area, in: Earthquake-Induced Landslides, Springer, 895-900, doi:10.1007/978-3-642-32238-9_97, 2013.

Zhuang, J.-Q., Cui, P., Peng, J.-B., Hu, K.-H., and Iqbal, J.: Initiation process of debris flows on different slopes due to surface flow and trigger-specific strategies for mitigating postearthquake in old Beichuan County, China, Environ. Earth Sci., 68, 1391-1403, 2012. 